\section{Academy exposes a sham}

Colin Norman, Washington

For years now, spokesmen for the Nixon administration have been touting the line that federal research and development expenditure are gradually being focused on programmes which will benefit society and help solve "critical domestic problems" in the United States. Such sentiments reached their zenith two years ago, in March 1972, when President Nixon sent his first, and only, message to Congress on science and technology. His statement was replete with rhetoric about a new partnership which would be forged between government, industry and the universities, to help bring the fruits of technology to the people.

But a committee of the National Academy of Engineering (NAE), the most prestigious engineering organisation in the United States, published a report last week which came close to suggesting that most of President Nixon's science and technology message has turned out to be a complete sham.

The committee states that "with a few exceptions, the vast technology developed by federally funded programs since World War II has not resulted in widespread 'spin offs' of secondary or additional applications of practical products, processes, and services that have made an impact on the nation's economic growth, industrial productivity, employment gains and foreign trade".

The committee's general thesis is that technology developed with federal funds probably hasn't been exploited for the good of the people (or at least for the good of corporate profitability) because "a p'ethora of structural and institutional barriers exist in the federal government and the private economy to prevent the efficient and effective utilisation of this technology". Furthermore, since there has never been a comprehensive effort to search out technology which can be usefully exploited, it is difficult to recommend policies in such a vacuum of knowledge.

The NAE's findings and conclusions are shared by many observers of federal science policy, including a few key members of Congress. It was only just over a year ago, for example, that the Senate passed, by a huge majority, a bill sponsored by Senator Edward M. Kennedy which would have given the National Science Foundation a large budget to bring federal research and development to bear on such critical problems as urban renewal, health care delivery and transportation.

The bill died because it was never approved by the House of Representatives, but the sentiment lives on. Just

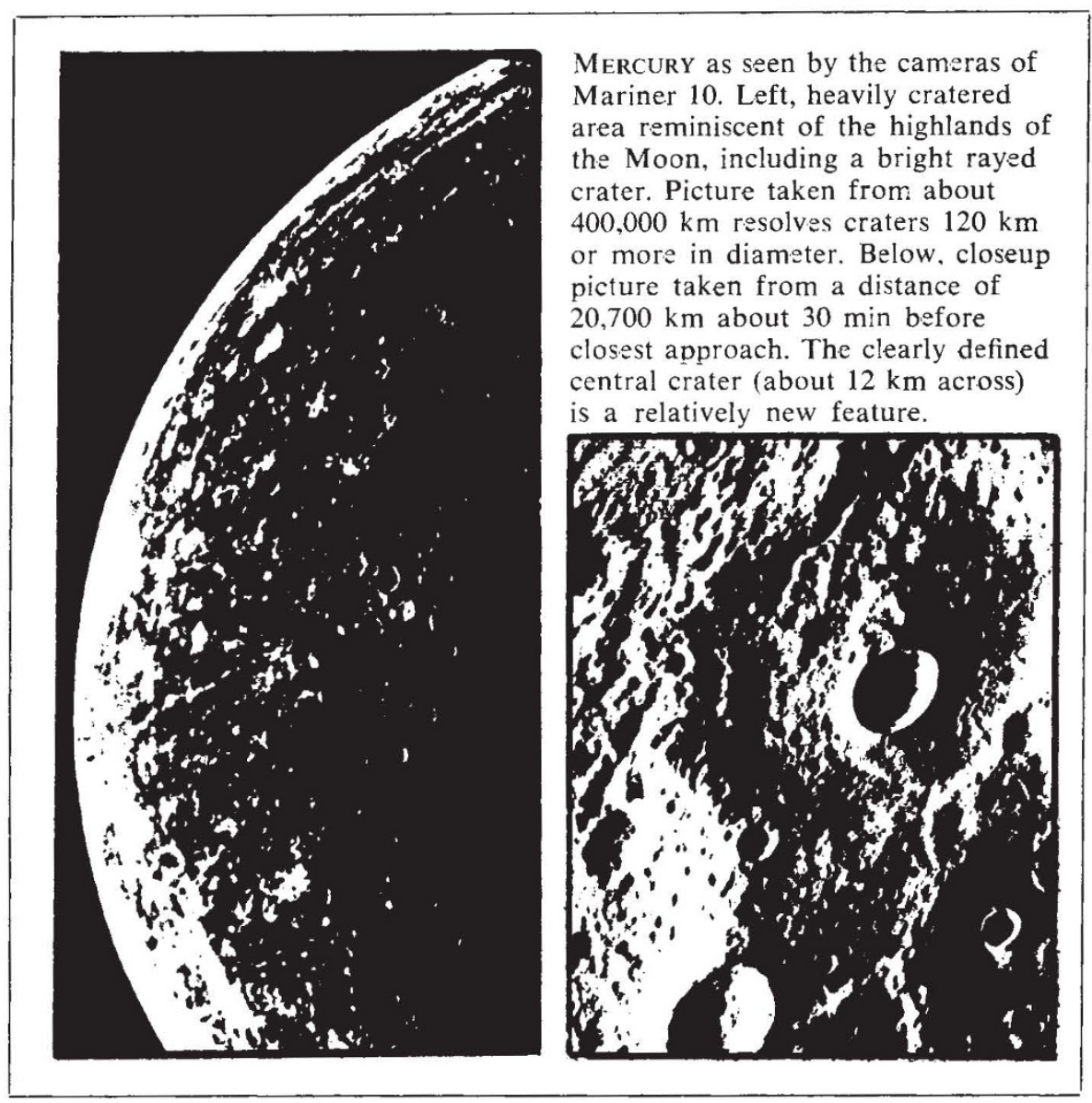

last month, for example, the Senate Committee on Science and Astronautics held extensive hearings on a bill which would provide NASA with a large helping of money to promote civilian technology. The bill is not likely to get anywhere this year because, even if it is approved by the Senate, the House of Representatives has so far shown little interest in the measure and in any case congress is likely to be occupied later this year with impeachment fever.

But there continues to be considerable feeling on Capitol Hill that there is a lot of federal research and development which cou'd be usefully exploited if only suitable arrangements could be worked out to accomplish the task.

The NAE committee, at least, has a few concrete recommendations for removing some of the barriers to innovation which have prevented private companies from turning federally produced technology into marketable products. For a start, it suggests that the federal government should spend $\$ 1,000$ million a year in helping to promote the utilisation of technology through a varisty of incentives and government programmes.

The first task should be to conduct a survey of federal laboratories, to test "the assumption that there is a substantial amount of useful federally funded technology available for beneficial, widespread secondary application."

Assuming, as the committee does, that the survey turns up positive results, federal agencies should set up explicit programmes with specific charters for embarking on technology utilisation projects, and they should be given funds earmarked in the agencies' budgets for that purpose. Certainly, some agencies, such as NASA, have already established such offices, but the NAE committee reckons that much more could be done. But the committee is quick to point out that its recommendations in no way "imply that the federal government should become a competitor to the private entreprensur", for the idea is that once a technology has been developed, it would be adapted, produced and marketed by private industry.

In order to stimulate that end of the process, the committee suggests that the federal government should provide a variety of incentives such as risk assurance, exclusive licences and "imaginatively bold financing to users in the public and private sectors in order to accelerate the direct implementation or to stimulate financial institutions to provide greater investment in new technology".

If all that sounds familiar, it is. Such suggestions have been made by virtually every committee which has studied the federal government's role in exploiting research and development financed by the taxpayer for the good of the taxpayer. But so far, there's little sign that anybody is listening. 